\title{
Dexamethasone-Loaded Bioactive Coatings on Medical Grade Stainless Steel Promote Osteointegration
}

\author{
Jan Rožanc ${ }^{1,2}$,, Marko Žižek $^{3}\left(\mathbb{D}\right.$, Marko Milojević $^{1,2}$, Uroš Maver ${ }^{1,2, *(1)}$ and Matjaž Finšgar ${ }^{3, *}$ \\ 1 Faculty of Medicine, Institute of Biomedical Sciences, University of Maribor, 2000 Maribor, Slovenia; \\ jan.rozanc@um.si (J.R.); marko.milojevic@um.si (M.M.) \\ 2 Faculty of Medicine, University of Maribor, 2000 Maribor, Slovenia \\ 3 Faculty of Chemistry and Chemical Engineering, University of Maribor, 2000 Maribor, Slovenia; \\ marko.zizek@student.um.si \\ * Correspondence: uros.maver@um.si (U.M.); matjaz.finsgar@um.si (M.F.)
}

check for

updates

Citation: Rožanc, J.; Žižek, M.; Milojević, M.; Maver, U.; Finšgar, M. Dexamethasone-Loaded Bioactive Coatings on Medical Grade Stainless Steel Promote Osteointegration. Pharmaceutics 2021, 13, 568 . https://doi.org/10.3390/ pharmaceutics13040568

Academic Editors:

Alessandra Adrover and Stefania Petralito

Received: 17 March 2021

Accepted: 13 April 2021

Published: 16 April 2021

Publisher's Note: MDPI stays neutral with regard to jurisdictional claims in published maps and institutional affiliations.

Copyright: (c) 2021 by the authors. Licensee MDPI, Basel, Switzerland. This article is an open access article distributed under the terms and conditions of the Creative Commons Attribution (CC BY) license (https:// creativecommons.org/licenses/by/ $4.0 /)$.

\begin{abstract}
In this study, a multilayer bioactive coating based on carboxymethyl cellulose (CMC) and dexamethasone (DEX) was prepared on medical-grade stainless steel (AISI 316LVM). Its aim was the controlled drug delivery of the incorporated anti-inflammatory drug, which at the same time promotes osteogenic differentiation of mesenchymal stem cells. Due to DEX's limited solubility in physiological fluids, which limits the loading capacity of coatings, it was further combined with $\beta$-cyclodextrin to increase its concentration in the bioactive coating. Controlled release of DEX from the multilayer coating was achieved in four steps: a "burst", i.e., very fast, release step (in an immersion interval of 0-10 $\mathrm{min}$ ), a fast release step (10-30 $\mathrm{min})$, a slow-release step (60-360 $\mathrm{min}$ ), and a plateau step (360-4320 $\mathrm{min}$ ), following a zero-order release or Higuchi model release mechanism. Successful layer-by-layer coating formation was confirmed using attenuated total reflectance Fourier transform infrared spectroscopy (ATR-FTIR). It was shown that the application of the coating significantly increases the hydrophilic character of AISI 316LVM, and also significantly increases the surface roughness, which is known to promote cell growth. In addition, electrochemical measurements demonstrated that the coating application does not increase the susceptibility of medical-grade stainless steel to corrosion. In vitro cell testing using all cell types with which such coatings come into contact in the body (osteoblasts, chondrocytes, and mesenchymal stem cells (MSCs)) showed very good biocompatibility towards all of the mentioned cells. It further confirmed that the coatings promoted MSCs osteogenic differentiation, which is the desired mode of action for orthopedic implants.
\end{abstract}

Keywords: dexamethasone; carboxymethyl cellulose; medical grade stainless steel; controlled drug release; electrochemistry

\section{Introduction}

By 2050, the proportion of the world's population aged 60 years and over will nearly double from $12 \%$ (in 2015 ) to $22 \%$. Of cause for concern is not only the total expected number of elderly persons but also the pace at which the population is ageing. According to the World Health Organization (Fact Sheets, Aging and Health), every single country is facing major challenges in ensuring that its health and social systems will survive this demographic shift unharmed [1].

An important aspect of aging is the accumulation of various molecular and cellular damage over time, which leads to a gradual decrease in physical (and mental) capacity [2]. Among the most critical consequences are diseases of the musculoskeletal system, including several bone-related diseases [3]. Osteoporosis, osteoarthritis, and others, often necessitate clinical interventions, including bone replacement (i.e., the implantation of artificial materials) [4]. 
Implantations have been part of regular clinical treatment for centuries. Despite this fact, the range of base materials is far from vast. Medical grade stainless steel (AISI 316LVM) is still among the most commonly used implant materials due to its low cost and other suitable properties (e.g., mechanical stability over time, corrosion resistance, biocompatibility) [5-7]. Nevertheless, none of the mentioned properties is optimal, especially considering the high life expectancy in the western world and the relatively low age at which such implantations (e.g., hip replacements) might occur. Namely, stability over 20 years is challenging for the most sophisticated of the current implants [8]. This is even truer for substrates such as AISI 316LVM with the above-mentioned long-term instabilities [9].

An increasingly interesting approach to improving AISI 316LVM lies in its functionalization with coatings intended to prolong its lifespan [10,11], increase fast osteointegration [12], and/or provide improved long-term corrosion resistance [13,14]. Various materials have been employed for this purpose (e.g., selenium nanoparticles [15], hydroxyapatite in various forms [16,17], polylactic acid [18], peptide coatings [19], etc.). However, it seems that most of the interest lies in biocompatible coatings based on polysaccharides, such as alginate (ALG), carboxymethyl cellulose (CMC), and others [12,20-23].

These and other studies report various approaches to coating preparation. However, the trend should be to ease the process. In contrast, the focus should be shifted towards improving their osteointegration potential (i.e., the promotion of osteogenic differentiation, osteoblast growth, and biomineralization) and/or towards coating stability, allowing for use in all kinds of implantations [24-27].

Dexamethasone (DEX) is a commonly applied glucocorticoid with a vast range of systemic pharmacodynamic effects. Among others, glucocorticoids are labeled antiinflammatory drugs in their purest essence, alleviating all levels of inflammation in the body. As part of systemic therapy, they are used to treat various inflammatory diseases [28] and the application of implants $[29,30]$. Furthermore, DEX was shown to boost osteogenic differentiation in a variety of studies [31,32]. Both of the mentioned effects, the multi-fold anti-inflammatory activity and osteogenic differentiation, make DEX an interesting drug to incorporate in coatings on metal implants in orthopedic applications.

However, the use of DEX and other glucocorticoids does not come without problems. Among these, its low solubility in water renders its inclusion in formulations harder than expected [33]. Due to the latter, solutions for its functionalisation were developed, including combinations of different polymers [33], the use of solubilizing agents [34,35], and the preparation of formulations based on "bimodal" materials with hydrophilic and lipophilic parts (e.g., cyclodextrins (CDs)) [36]. Although the literature reports some examples of DEX combinations, to the best of our knowledge, our study is the first to combine $\beta$-cyclodextrin $(\beta-C D)$ with DEX to prepare coatings on metal implants for orthopedic applications.

This work reports on the development and characterization of new bioactive and biocompatible coatings on AISI 316LVM. The coatings consisted of carboxymethylcellulose $(\mathrm{CMC})$ and dexamethasone (DEX). A multilayer coating of alternating CMC and DEX layers was developed to provide a bioactive therapeutic treatment platform for an antiinflammatory effect and simultaneous osteogenic differentiation. Both effects are achieved by successfully manipulating the coating composition (including the concentration of DEX) and drug release mechanisms. Detailed characterization of the coating was performed by attenuated total reflectance Fourier transform infrared spectroscopy (ATR-FTIR), contact angle measurements, and atomic force microscopy (AFM). In addition, the corrosion susceptibility of AISI 316LVM before and after the application of these coatings was checked by electrochemical impedance spectroscopy (EIS) and cyclic polarization measurements (CP). Finally, the coatings' functional properties were determined by evaluating their in vitro release performance and cell testing using human tissue-based cells that come into contact with orthopedic implants. These included mesenchymal stem cells (MSCs), osteoblasts, and chondrocytes. 


\section{Experimental}

\subsection{Sample Preparation}

The AISI 316LVM samples were cut out from a 2-mm-thick plate in the shape of discs with a diameter of $15 \mathrm{~mm}$. The discs were ground on a rotating grounding device with 320 and 500-grit $\mathrm{SiC}$ papers (Struers, Ballerup, Denmark) under a water stream until the surface layer was removed and unidirectional scratches were visible. The grinding leftovers and any possible fatty residues were removed by immersion in an ultrasonic bath for $5 \mathrm{~min}$. This bath contained $50 \mathrm{vol} . \%$ ethanol $/ 50$ vol. $\%$ ultrapure water. Ultrapure water, with a resistivity of $18.2 \mathrm{M} \Omega \mathrm{cm}$ at $25.0^{\circ} \mathrm{C}$, was obtained with the Milli- ${ }^{\circledR}$ system, supplied by EMD Merck KGaA, Darmstadt, Germany. As-prepared substrates were passivated for $1 \mathrm{~h}$ in $30 \mathrm{wt} . \%$ nitric acid (purity $\geq 65 \%$, Sigma Aldrich, St. Louis, MO, USA), rinsed with ultrapure water, and dried under a stream of air. Electrochemical measurements were performed in 0.9 wt.\% solution of $\mathrm{NaCl}(\mathrm{NaCl}$ was pro analysis, supplied by Carlo Erba Reagents, Italy). A solution of $0.9 \mathrm{wt} . \% \mathrm{NaCl}$ was employed as it is the main compound in body fluid, which causes corrosion.

\subsection{Solutions and Coatings Preparation}

CMC solution (containing 0.5 wt.\% CMC) was prepared using CMC (low viscosity, Sigma Aldrich, St. Louis, MO, USA) and ultrapure water. As the solubility of DEX in water is very low $\left(89 \mathrm{mg} / \mathrm{L}\right.$ at $\left.25^{\circ} \mathrm{C}\right)[33,37]$, increased solubility can be achieved with the addition of $\beta-C D[38,39]$. $\beta-C D$ with a purity $\geq 97 \%$ was used for this purpose (Sigma Aldrich). The mass concentration ratio of DEX: $\beta-C D$ was $1: 8$. The mentioned ratio was chosen based on the solubility data of DEX and $\beta-C D$ from the literature [40], as well as considering the fact that in the solution with this ratio, all DEX, even at a concentration of $2.5 \mathrm{mg} / \mathrm{mL}$, was possible to dissolve. At a higher concentration of $\beta-\mathrm{CD}$ an undissolved residue remained in the solution.

Two DEX solutions were prepared, i.e., solutions named DEX1 (containing $1 \mathrm{mg} / \mathrm{mL}$ DEX; Sigma-Aldrich, Darmstadt, Germany) and DEX2.5 (containing $2.5 \mathrm{mg} / \mathrm{mL}$ DEX). Both solutions were prepared in ultrapure water and placed for $5 \mathrm{~min}$ in an ultrasonic bath.

$\beta-C D$ and DEX were weighed into separate glass flasks. To prepare the $\beta-C D$ solution, a flask was halfway filled with ultrapure water. The weighed $\beta-C D$ amount was transferred into the flask, followed by adding the weighed DEX amount. The flask was filled with ultrapure water to the top of the flask's neck. Despite extensive mixing, some sediment was still present. For this purpose, the flask was placed in an ultrasonic bath for $5 \mathrm{~min}$ (the procedure was repeated, if necessary). When there was no visible sediment left in the flask, the flask was filled up to the mark. The solution was then filtered into glass containers with lids (using syringes with filter nozzles).

As-prepared AISI 316LVM samples (as described in Section 2.1) were placed in the center of a POLOS SPIN-150i-NPP spin coater (SPS Vertriebs GmbH, Germany) and held in place with a vacuum pump. To ensure even spreading of the first layer, $200 \mu \mathrm{L}$ of CMC solution was placed in the center of the substrate surface, and the sample was spun. The spinning parameters were the same for every layer application: spinning velocity $2500 \mathrm{rpm}$, acceleration $500 \mathrm{rpm} / \mathrm{s}$, and spinning time $180 \mathrm{~s} .100 \mu \mathrm{L}$ of the DEX solution (either DEX1 or DEX2.5) was placed in the center of the CMC-coated substrate to apply the second layer. Next, an additional CMC layer was applied by placing $100 \mu \mathrm{L}$ of CMC solution on the previously coated surface. A multilayer coating was formed on the substrate by alternately adding the CMC and the DEX layers, as schematically depicted in Figure 1. Coated samples were named $3 C M C x D E X y$, where 3 and $x$ are the number of layers and $y$ is the concentration of the DEX solution. Depending on the DEX solution used, the samples were named 3CMC3DEX1, 3CMC2DEX1, 3CMC3DEX2.5, and 3CMC2DEX2.5, where the DEX1 and DEX2.5 terms stand for the solution used to prepare these coatings (as described above). 


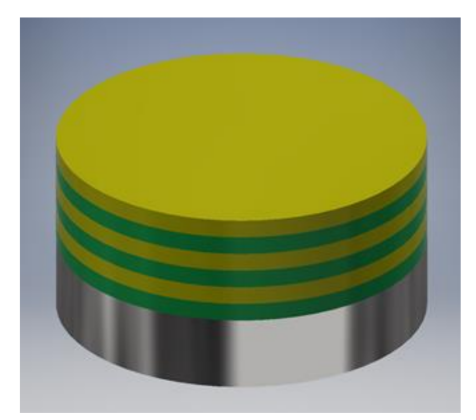

Figure 1. Representation of the multilayer coating design (the green layer is CMC and the yellow layer is DEX solubilised with $\beta-C D)$.

\subsection{Coating Characterisation}

The alternating multilayer coating formation was investigated by means of ATR-FTIR measurements using an Agilent Cary 630 FTIR spectrometer with a diamond ATR module (Agilent Technologies, Santa Clara, CA, USA). ATR-FTIR measurements were performed in the $4000-630 \mathrm{~cm}^{-1}$ wavenumber range.

Contact angle (CA) measurements were performed with an OCA 200 device (DataPhysics Instruments GmbH, Filderstadt, Germany). A $1 \mu \mathrm{L}$ droplet of ultrapure water was placed on a sample, and the droplet was photographed. The image was then processed with SCA software (DataPhysics Instruments $\mathrm{GmbH}$, Filderstadt, Germany). The contact angle was determined as the angle between the sample surface and the droplet's tangential border line at the three-phase contact point [41].

An evaluation of the topography properties and roughness parameters of the coated samples was performed by AFM in tapping mode. A Keysight Technologies 7500 AFM device was used (Keysight Technologies, Santa Barbara, CA, USA). Before acquiring images, the samples were dried under a stream of dry high-grade (99.999 vol.\%) nitrogen. The scanning was performed using ATEC-NC-20 silicon cantilevers (Nanosensors, Germany) with a force constant of $12-110 \mathrm{~N} / \mathrm{m}$ and a resonance frequency of $210-490 \mathrm{kHz}$. The imaging was performed at room temperature. Each sample was scanned at a size of $10 \times 10 \mu \mathrm{m}^{2}$ and $1 \times 1 \mu \mathrm{m}^{2}$ with a resolution of $2048 \times 2048$ pixels [6]. The corresponding roughness parameters were calculated using PicoImage software (Keysight Technologies, Santa Barbara, CA, USA) [6].

\subsection{In Vitro Drug Release}

An Automated Transdermal Diffusion Cells Sampling System (Logan System 912-6, Somerset, NJ, USA) was used to analyze the drug release behavior. The coated samples were placed in Franz diffusion cells, filled with phosphate-buffered saline-PBS $(0.137 \mathrm{M}$ $\mathrm{NaCl}, 0.01 \mathrm{M}$ phosphate buffer, and $0.0027 \mathrm{M} \mathrm{KCl} ; \mathrm{pH} 7.4$ at $25^{\circ} \mathrm{C}$ ). PBS tablets (SigmaAldrich, Germany) were used to prepare these solutions. The coated side of the immersed sample was facing up. The temperature during the experiments was kept stable at $37^{\circ} \mathrm{C}$. The magnetic bar for stirring the medium during the experiment (50 rpm) was placed below the diffusion cell. Samples of $1 \mathrm{~mL}$ were collected in different intervals $(1 \mathrm{~min}, 5 \mathrm{~min}$, $10 \mathrm{~min}, 20 \mathrm{~min}, 30 \mathrm{~min}, 60 \mathrm{~min}, 120 \mathrm{~min}, 180 \mathrm{~min}, 240 \mathrm{~min}, 300 \mathrm{~min}, 360 \mathrm{~min}, 1440 \mathrm{~min}$, $2880 \mathrm{~min}$, and $4320 \mathrm{~min}$ ). The volume of the collected samples was replaced with fresh PBS at $37^{\circ} \mathrm{C}$. The concentration of released DEX was measured by UV/VIS spectrophotometry (Cary 60 UV-Visible Spectrophotometer, Agilent, Waldbronn, Germany) at a wavelength of $241 \mathrm{~nm}$. The dilution effect from sample withdrawal and media replacement was accounted for in the concentration calculations using the Beer-Lambert law. To determine how many different release stages are present, the first derivative of the cumulative mass $\left(\mathrm{d}\left(m_{\text {norm }} / m_{\max }\right) / \mathrm{d} t\right)$ was calculated and plotted, where $m_{\text {norm }}$ and $m_{\max }$ stand for the mass of all released DEX until a certain time point, and the total released/incorporated DEX, respectively, while $t$ stands for the release time. The release kinetics were subsequently 
tested with commonly applied mathematical models for drug release. These included zero order, first order, Hixson-Crowel, Higuchi, and Korsmeyer-Peppas models [12].

\subsection{Electrochemical Measurements}

All electrochemical measurements were performed in a $0.9 \mathrm{wt} . \% \mathrm{NaCl}$ solution, in a glass electrochemical cell at $37^{\circ} \mathrm{C}$ (controlled by a thermostat), and were executed using Autolab PGSTAT204 (Metrohm Autolab, Utrecht, Holland). A saturated calomel electrode (SCE) and a graphite rod were used for reference and counter electrodes, respectively. The working electrodes were uncoated and coated samples inserted in a Teflon holder, sealed with an o-ring. The area of the working electrode exposed to the solution was $1 \mathrm{~cm}^{2}$.

Chronopotentiometry, EIS, and CP curve measurements were performed in sequence, starting with chronopotentiometry the moment after sample immersion in the solution for up to $1 \mathrm{~h}$ of immersion. Then an EIS measurement was performed. Afterwards, a chronopotentiometry measurement for up to $3 \mathrm{~h}$ of immersion was performed. This procedure was repeated until EIS measurements were collected after 1, 3, 5, 7, 10, 15, 20, $24,36,48,60$, and $72 \mathrm{~h}$ of immersion. Finally, a CP measurement was performed after $72 \mathrm{~h}$ of immersion.

EIS measurements were performed at the open circuit potential $\left(E_{\mathrm{oc}}\right)$ in the $5 \mathrm{mHz}-$ $1 \mathrm{MHz}$ frequency range using a $10 \mathrm{mV}$ peak-to-peak amplitude. The obtained EIS data were fitted with ZView2 software (Scribner Associates Inc., Southern Pines, NC, USA). CP measurements started at $-0.250 \mathrm{~V}$ vs. $E_{\mathrm{oc}}$ potential and a potential sweep rate of $0.1 \mathrm{mV} / \mathrm{s}$ in the anodic direction. When the current density (i) reached a value of $1 \mathrm{~mA} / \mathrm{cm}^{2}$, the potential sweep was reversed in the cathodic direction until the starting potential was reached.

\subsection{In Vitro Cell Response}

Three different cell types were used to assess the in vitro response. Human adiposederived mesenchymal stem cells (hADMSC) (PCS-500-011, ATCC, Botolph Claydon, UK) (passages 2-4) were grown in mesenchymal stem cell basal medium supplemented with an MSC growth kit (ATCC, UK) and $1 \mathrm{wt} . \%$ penicillin/streptomycin. Human bone tissuederived osteoblasts (CRL-11372, ATCC, UK) were grown in Advanced ADMEM supplemented with $5 \mathrm{wt} . \%$ FBS and $1 \mathrm{wt} . \%$ penicillin/streptomycin. Human articular chondrocytes were isolated and characterized as described previously [42] and grown in Advanced ADMEM supplemented with $5 \mathrm{wt} . \%$ FBS and $1 \mathrm{wt} . \%$ penicillin/streptomycin.

For observation of the cell morphology, the cells were seeded on the coated and uncoated AISI 316LVM samples in a 24-well plate at a density of $4 \cdot 10^{4}$ cells/well and incubated for $48 \mathrm{~h}$. Phalloidin $(1000 \times$ Phalloidin stock solution in dimethyl sulfoxide DMSO (Abcam, UK), 1/1000 dilution in PBS with $1 \mathrm{wt}$ \% bovine serum albumin (BSA; SigmaAldrich, Munich, Germany), and 0.1 wt.\% Tween 20 (Sigma-Aldrich, Munich, Germany)) was used to stain for actin filaments. After $90 \mathrm{~min}$ of incubation at room temperature and in a dark room, the cells were washed, and Fluoroshield Mounting Medium with 4',6-diamidino-2-phenylindole DAPI was used to stain the nuclei. The cells were visualized using a fluorescent microscope (EVOS FL, Thermo Fisher Scientific, Waltham, MA, USA) at suitable wavelengths for the respectively used dyes (excitation/emission: DAPI = $306 / 460 \mathrm{~nm}$ and Phalloidin $=556 / 574 \mathrm{~nm}$ ).

To determine cell viability, a tetrazolium salt MTT (3(4,5 dimethylthiazolyl-2)-2,5diphenyltetrazolium bromide) assay was used (Sigma-Aldrich, Steinheim, Germany). Briefly, cells were seeded onto the prepared experimental and control substrates at a density of $4 \cdot 10^{4}$ cells/well in a 24-well plate. After 3 and 6 days of incubation at $37^{\circ} \mathrm{C}$ and $5 \mathrm{wt} . \% \mathrm{CO}_{2}$, the medium was removed and the cells were washed with PBS, followed by the addition of $250 \mu \mathrm{l}$ of MTT assay solution and incubated for $2 \mathrm{~h}$ at $37^{\circ} \mathrm{C} .100 \mu \mathrm{L}$ aliquots of the culture solution from each sample were then transferred to a 96-well plate and the absorbance was measured spectrophotometrically at $570 \mathrm{~nm}$ using a Varioskan multiplate reader (ThermoFisher, Dreieich, Germany). 
In order to assess the osteogenic and chondrogenic differentiation potential of MSCs on CMC/DEX-coated substrates, the expression of osteogenic (collagen type I (COLIA1) and osteocalcin (OCN)) and chondrogenic (collagen type II (COLIIA1) and aggrecan (AGR)) protein markers were evaluated. Briefly, cells were seeded onto the samples placed in a 24-well plate at a concentration of $2.5 \times 10^{4}$ cells/well and incubated for 14 and 21 days. The medium was changed once a week. After incubation, the cells were fixed with a Fixation solution (Merck KGaA, Darmstadt, Germany) and the following antibodies were used for immunostaining to assess the expression of the protein markers: $\mathrm{Rb} \mathrm{pAb}$ antiCOLIA1 (Abcam, Cambridge, UK), Rb pAb anti-COLIIA1 (Abcam, Cambridge, UK), Ms mAb anti-AGR (Abcam, Cambridge, UK), Goat pAb to Rb-AF 594 (Abcam, Cambridge, $\mathrm{UK}$ ), $\mathrm{Rb}$ pAb to Ms-AF 488 (Abcam, Cambridge, UK), and Rb pAb anti-OCN-AF488 (Bioss, Woburn, MA, USA).

\section{Results and Discussion}

Novel materials intended for biomedical applications require a series of analyses to understand their properties in a targeted environment and to assess their safety and efficiency in contact with cells at the target site in the body $[43,44]$. Since an anti-inflammatory and osteogenesis-boosting coating for "long-term" orthopedic applications was developed (e.g., hip replacements), most of the tests performed were oriented towards controlling the main coating composition, long-term stability, drug release performance, and cell response with tissue-specific target cells.

\subsection{Multilayer Structure Characterisation}

To confirm the multilayer structure of the coating on the AISI 316LVM, ATR-FTIR measurements were performed for the respective DEX and CMC layers. Figure 2 shows the spectra for the uncoated AISI 316LVM and all successive layers (from bottom to top), forming the final 3CMC3DEX coating. Each application of a DEX coating layer results in the formation of an intense ATR-FTIR peak (marked within the dashed lines shown in Figure 2). After adding a CMC layer, the characteristic peaks for DEX (almost completely) disappear, indicating that the CMC coating effectively covered the DEX layer. These ATR-FTIR spectra, therefore, show the successful layer-by-layer build-up of the multilayer CMC-DEX coating. Furthermore, a comparison of the spectra for all the components included in the coatings (CMC, DEX, and $\beta-C D)$ is shown in Figure S1 (Supplementary Materials). An overlay of the spectra for DEX, $\beta-C D$, and their mixed solution is shown in Figure S2 (Supplementary Materials).

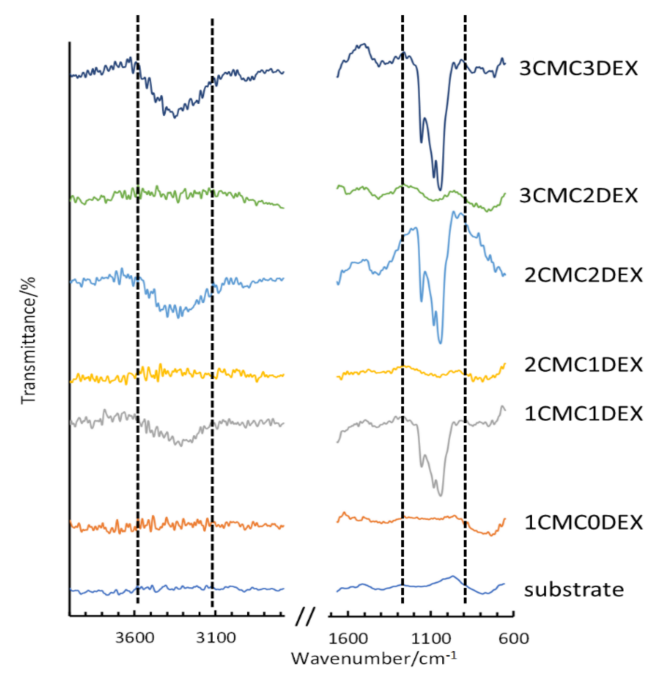

Figure 2. ATR-FTIR measurements on AISI 316LVM after successive application of alternating CMC and DEX layers. 


\subsection{Hydrophobicity Measurements}

The contact angles were measured for the uncoated and coated samples. The results are given in Table 1. For all coated samples, the contact angle decreased significantly, indicating the hydrophilic nature of the main polymer component (CMC) of the coatings. When DEX was in the top-most layer (a six-layer coating), the contact angle dropped slightly compared to the coating with CMC as the top-most layer (a five-layer coating); however, this change is not significant. Furthermore, another conclusion can be made based on these results. Namely, the insignificant changes in hydrophilicity between the samples with DEX and CMC as the top-most layer, respectively, show that, despite the alternating CMC/DEX structure being confirmed using ATR-FTIR, the main coating character is nevertheless defined by the polymer. The latter plays an important part in the coating's observed dissolution behavior, where surface wetting importantly contributes to successful control of the drug release (see below, Section 3.3).

Table 1. Measured contact angles.

\begin{tabular}{cc}
\hline Sample & Contact Angle $\left.{ }^{\circ}{ }^{\circ}\right]$ \\
\hline BLANK & $83.04 \pm 4.07$ \\
3CMC3DEX1 & $4.94 \pm 0.22$ \\
3CMC2DEX1 & $4.69 \pm 0.21$ \\
3CMC3DEX2.5 & $2.67 \pm 0.19$ \\
3CMC2DEX2.5 & $2.32 \pm 0.21$ \\
\hline
\end{tabular}

\subsection{Coating Topography and Morphology Evaluation Using AFM}

In order to evaluate the influence of the prepared coatings on the substrate topography and roughness, AFM was used on two scan sizes $\left(10 \times 10\right.$ and $\left.1 \times 1 \mu \mathrm{m}^{2}\right)$ (Figure 3). Upon first examination, successful coating application and, with it, significantly changed surface features (i.e., topography), are immediately evident. The parallel running surface features of the substrate (introduced through grinding, as described in the Experimental section) are evident for all samples, except for the final sample, i.e., 3CMC3DEX2.5, whose top-most layer was loaded with the higher drug concentration. While the first applied coating with the lower drug concentration (3CMC2DEX1) did not significantly increase the surface roughness, the subsequent samples gradually increased the surface roughness in an expected pattern. Namely, by increasing the number of applied layers and increasing the drug concentration the roughness parameters increase. This is also evident from the obtained AFM images (showing the obtained sample topographies). One interesting phenomenon observed is the presence of "sphere-like" shapes starting with the first applied coating (3CMC2DEX1), which disappear in the final sample (3CMC3DEX2.5), where these surface features seem to have "coalesced" into bigger structures. The appearance of these bigger structures also led to a clear jump in the roughness parameters (comparing this sample to any of the others). In contrast to one of our previous studies, in which CMC was used as part of a coating with a different drug-loaded [12], here no smooth surface can be observed. In the present study, the drug-polymer coatings seem to have formed a different kind of organization, which leads to increased surface roughness compared to the mentioned study and very different topography. The latter includes surface features beyond the ones formed by grinding. An interesting result is also that despite the increased roughness due to the increased DEX concentration (when comparing the samples with CMC as the top-most layer, i.e., 3CMC2DEX1 and 3CMC2DEX2.5), the topography seems to be "smoother", as shown in the AFM images of the samples with a higher DEX concentration. Furthermore, in the case of samples with DEX as the top-most layer, the roughness, and observable topography indicate the same trend.

Similar observations can be made based on the concrete measured roughness parameters, which confirms that adding a DEX layer at the top and increasing the DEX concentration in the coatings increases the surface roughness. Such an increased surface 
roughness favours cell attachment and is an important improvement of the base substrate properties in terms of applicability as part of orthopaedic implants [45,46].

\subsection{In Vitro Drug Release}

Controlled in vitro drug release is a much-desired property of multilayer coatings in almost any biomedical application. In this study, the coatings were examined by evaluating their drug release performance from various perspectives. Figure 4a shows that the DEX concentration increases and decreases with increasing $t$. Such behavior fits well with the multilayer coating structure, where CMC and DEX layers are present in an alternating manner. The maximum amount of released DEX was determined by plotting the cumulative mass of DEX release over time (Figure $4 \mathrm{~b}$ ). As expected, the additional DEX layer in the six-layer coating (3CMC3DEX1 and 3CMC3DEX2.5) leads to higher cumulative DEX release compared to the five-layer coating (3CMC2DEX1 and 3CMC2DEX2.5). Figure 4c shows that all four coatings follow the same four-stage drug release mechanism (the separation of the first three stages is shown in Figure $4 \mathrm{~d}$, which presents the first derivative of the release profiles given in Figure 4c). Stage 1 (0-10 min) represents a "burst" release stage in which high amounts of DEX are released almost immediately (in clinical terms, this leads to rapid achievement of the therapeutic drug concentration). Stage 2 (10-30 min) represents a "fast" release stage, where a high release rate of DEX is still achieved, but more slowly than in the "burst" stage (in clinical terms, this still increases the drug concentration and contributes to the maximal drug concentration). In stage 3 (60-360 $\mathrm{min}$ ) the release rate slows down and remains constant over time (which means that the drug concentration starts to fall slowly yet remains in a concentration interval that maintains the therapeutic effect). The last stage, stage 4 ( $360-4320 \mathrm{~min})$, is the so-called "plateau" stage in which the release rate is the slowest, and the remaining DEX is released from the coating (the concentration slowly falls, and another dose would be required in a clinical setting during this stage).

\section{Mathematical Modelling of the Drug Release Stages}

All identified release stages in Figure 4 were fitted using five common mathematical release models by converting the data into the respective parameters given in Table 2 . In the table, $w$ is the mass fraction of released DEX, $Q_{\max }(\%)$ is the maximum amount of released DEX, and $Q_{\mathrm{t}}(\%)$ is the amount of released DEX at a given $t$. These parameters were plotted as required to fit the data with respective release models in order to obtain a linear trend line. The latter was then used to obtain the square of the correlation coefficient $\left(R^{2}\right)$. The release model with the highest $R^{2}$ value, i.e., for which the $R^{2}$ value was closest to 1.000 , was considered to be the most probable to explain the release mechanism for the respective stage. The obtained $R^{2}$ values are given in Table 3 . 


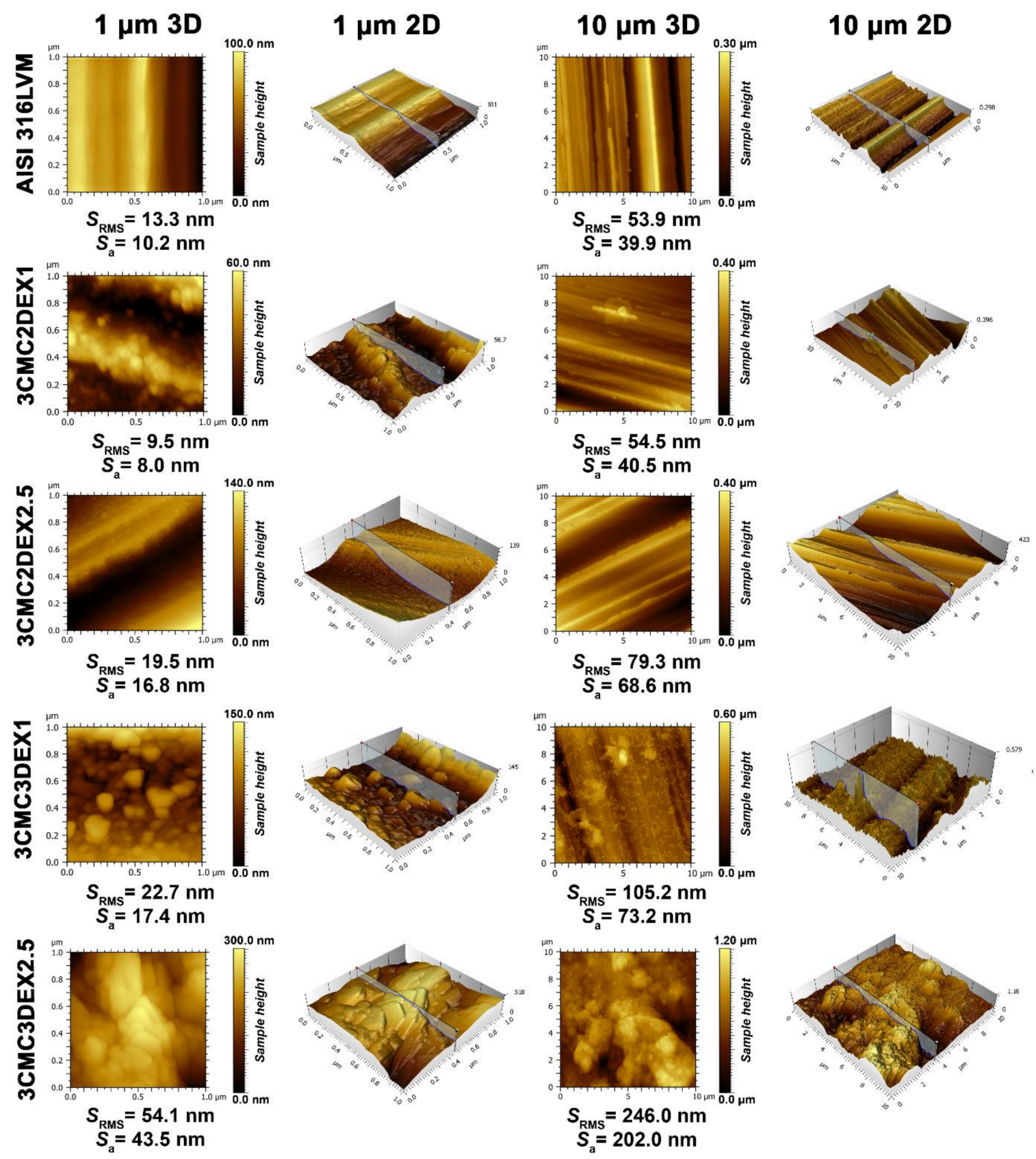

Figure 3. AFM topography measurements for all samples and AISI 316LVM in 2D and 3D, accompanied by the corresponding roughness parameters. 

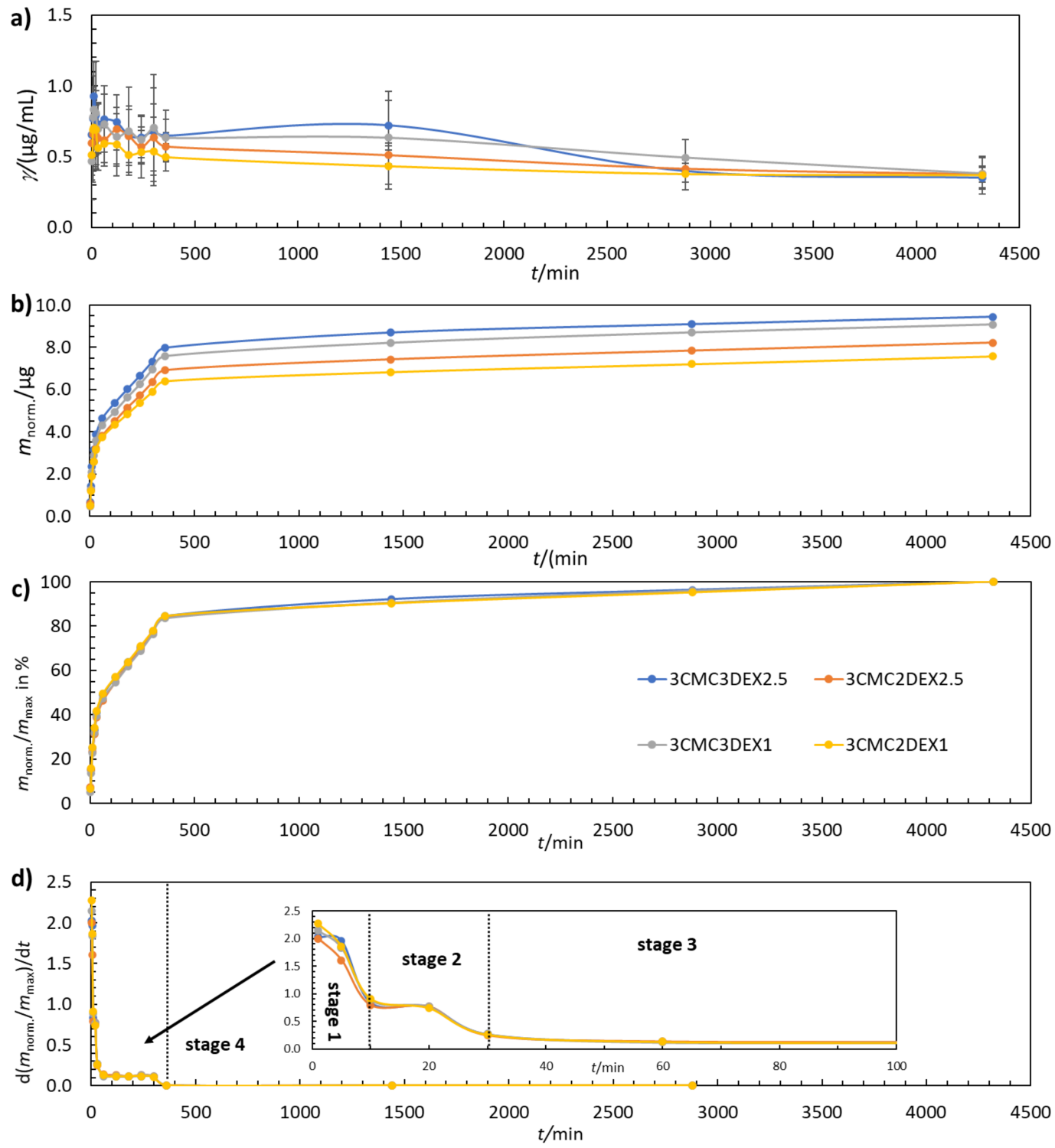

Figure 4. (a) The change in DEX concentration during drug release testing, (b) the cumulative mass of the released DEX, (c), the normalised mass of the released DEX, and (d) the first derivative of the released amount of DEX for coated samples. The error bars in (a) represent $95 \%$ confidence intervals.

Table 2. Mathematical drug release models with corresponding plotting parameters.

\begin{tabular}{cc}
\hline Model & Plotting \\
\hline ZERO ORDER & $w$ vs. $t$ \\
FIRST ORDER & $\log w$ vs. $t$ \\
HIXSON-CROWELL & $Q_{\max }^{1 / 3}-Q_{\mathrm{t}}^{1 / 3}$ vs. $t$ \\
HIGUCHI & $w$ vs. $t^{1 / 2}$ \\
KORSMEYER-PEPPAS & $w$ vs. $\log t$ \\
\hline
\end{tabular}


Table 3. Mathematical release model determination by comparing the fitting parameter $R^{2}$. The bold underlined values represent the best fit and hence the most suitable model to describe the respective release stages for the four tested samples.

\begin{tabular}{|c|c|c|c|c|c|}
\hline Model & Stage & 3CMC3DCF1 & 3CMC2DCF1 & 3CMC3DCF2.5 & 3CMC2DCF2.5 \\
\hline ZERO ORDER & & $\underline{0.9999}$ & $\underline{0.9961}$ & $\underline{0.9980}$ & $\underline{0.9967}$ \\
\hline FIRST ORDER & & $\overline{0.9654}$ & $\overline{0.9518}$ & $\overline{0.9415}$ & $\overline{0.9461}$ \\
\hline HIXSON-CROWELL & I & 0.9837 & 0.9716 & 0.9681 & 0.9691 \\
\hline HIGUCHI & & 0.9813 & 0.9929 & 0.9897 & 0.9921 \\
\hline KORSMEYER-PEPPAS & & 0.9235 & 0.9491 & 0.9413 & 0.9469 \\
\hline ZERO ORDER & & 0.9994 & 0.9999 & 0.9982 & 0.9965 \\
\hline FIRST ORDER & & 0.9912 & 0.9931 & 0.9861 & 0.9835 \\
\hline HIXSON-CROWELL & II & 0.9950 & 0.9965 & 0.9913 & 0.9889 \\
\hline HIGUCHI & & 0.9973 & 0.9957 & 0.9989 & 0.9997 \\
\hline KORSMEYER-PEPPAS * & & 0.9841 & 0.9806 & $\overline{0.9885}$ & $\overline{0.9917}$ \\
\hline ZERO ORDER & & 0.9995 & 0.9990 & 0.9998 & 0.9996 \\
\hline FIRST ORDER & & $\overline{0.9905}$ & $\overline{0.9863}$ & $\overline{0.9935}$ & $\overline{0.9906}$ \\
\hline HIXSON-CROWELL & III & 0.9950 & 0.9923 & 0.9971 & 0.9950 \\
\hline HIGUCHI & & 0.9884 & 0.9908 & 0.9838 & 0.9887 \\
\hline KORSMEYER-PEPPAS * & & 0.9655 & 0.9834 & 0.9725 & 0.9872 \\
\hline ZERO ORDER & & 0.9987 & 0.9992 & 0.9944 & 1.0000 \\
\hline FIRST ORDER & & $\overline{0.9977}$ & $\overline{0.9982}$ & 0.9921 & $\overline{0.9996}$ \\
\hline HIXSON-CROWELL & IV & 0.9980 & 0.9986 & 0.9929 & 0.9998 \\
\hline HIGUCHI & & 0.9984 & 0.9977 & 1.0000 & 0.9950 \\
\hline KORSMEYER-PEPPAS * & & / & / & / & / \\
\hline
\end{tabular}

* The model is considered valid for only up to $60 \%$ of the maximal total of the released drug.

Both DEX1-containing coatings, i.e., 3CMC3DCF1 and 3CMC2DCF1, follow the zeroorder release model in all four steps. This means that the release kinetics are not affected by the drug concentration. Coatings containing DEX2.5 (3CMC3DCF2.5 and 3CMC2DCF2.5) follow the zero-order model in stages 1 and 3, while in stage 2 they follow the Higuchi model. The Higuchi model describes drug release as a diffusion-controlled process. The model is based on Fick's law, depending on the square root of $t$. Considering the latter, it seems that the coatings with a higher DEX load achieved internal saturation of the dissolved drug, which limited the maximal drug release from 3CMC3DCF2.5 and 3CMC2DCF2.5. In the coatings with a lower DEX load (3CMC3DCF1 and 3CMC2DCF1), the internal concentration in the coatings was not high enough to limit the overall release rate. From a practical perspective regarding the application of such coatings, the incorporated concentration of DEX should be less than the $2.5 \mathrm{mg} / \mathrm{mL}$ used to allow for more straightforward control over patient-tailored drug release performance. In stage 4, 3CMC3DEX2.5 continues to follow the Higuchi model, while 3CMC2DEX2.5 returns to zero-order model release.

\subsection{Long-Term Stability-The Corrosion Susceptibility of the Coated Samples}

Electrochemical measurements were carried out to check whether the applied coatings significantly influenced the susceptibility to corrosion of the AISI 316LVM samples. Corrosion susceptibility was investigated in a $0.9 \mathrm{wt} . \% \mathrm{NaCl}$ solution, which is the most important corrosive medium in body fluids. The tests were carried out at $37^{\circ} \mathrm{C}$ to simulate the conditions in the human body. At least three replicate measurements were performed, followed by an EIS fitting procedure. The obtained fitted parameters for the replicate measurements were checked for possible outliers using the Grubbs' test [47], and if detected they were discarded. The reported values were average values calculated with at least three values without outliers.

Figure 5 shows measured and fitted EIS data for the coated samples (one of three replicate measurements is given for each system). In order to explain the electrochemical mechanism of the coated samples in $0.9 \mathrm{wt} . \% \mathrm{NaCl}$ solution, several possible equivalent electrical circuits (EEC) were used to fit the EIS response. The goodness of the fitting procedure was evaluated with the $c^{2}$ value [48], i.e., the lower the $c^{2}$, the better the obtained fit, and the probability that the EEC employed is accurate is higher. The EEC with the 
lowest $c^{2}$ was $R_{\Omega}\left(Q_{2}\left(R_{2}\left(Q_{1} R_{1}\right)\right)\right.$ ) ( $R$ and $Q$ stand for the resistance and constant phase element, respectively). $R_{\Omega}$ represents the uncompensated resistance. The element $Q$ in this case represents the capacitance $C$, according to $C_{\mathrm{x}}=\left(R_{\mathrm{x}} Q_{\mathrm{x}}\right)^{1 / n \mathrm{x}} / R_{\mathrm{x}}$ [49-51]. The impedance of $C P E$ is $Z(C P E)=\left(Q(j w)^{n}\right)^{-1}$, where the symbols $Z, j, w$, and $n$ represent the impedance, imaginary unit $\left(j^{2}=1\right)$, angular frequency, and CPE power, respectively. In the present fitting procedure, $n$ was close to 1 , confirming that $Q$ represents $C$.
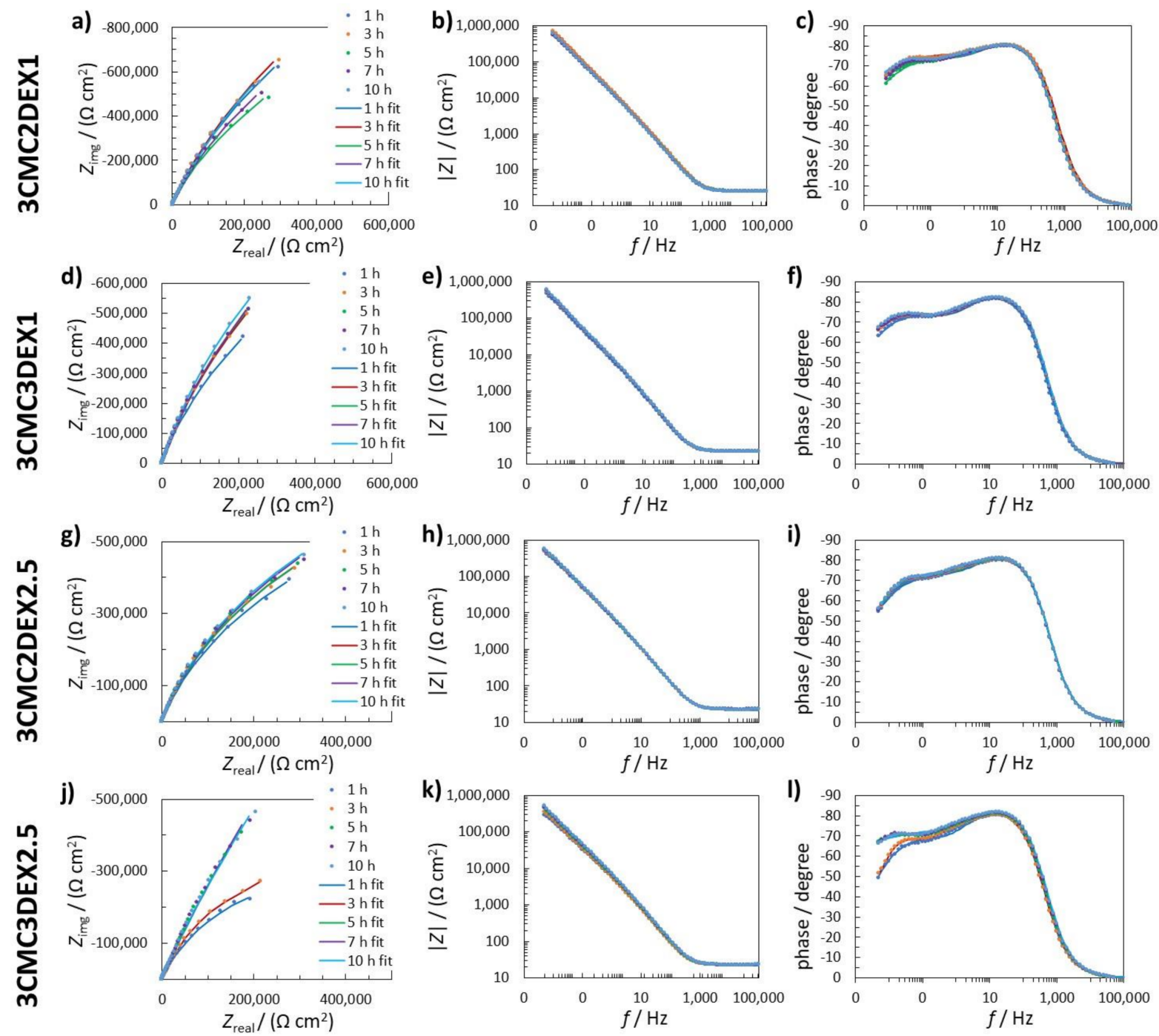

Figure 5. (a,d,g,j) Nyquist impedance; $(\mathbf{b}, \mathbf{e}, \mathbf{h}, \mathbf{k})$ Bode impedance; and $(\mathbf{c}, \mathbf{f}, \mathbf{i}, \mathbf{l})$ phase angle EIS spectra measured in 0.9 wt.\% NaCl solution for (a-c) 3CMC2DEX1; (d-f) 3CMC3DEX1; (g-i) 3CMC3DEX1; and (j-1) 3CMC3DEX1 samples. The measured data are represented with dots, whereas fitted data are given as solid lines.

The first time constant $\left(Q_{1} R_{1}\right)$ denotes the electrochemical properties of the doublelayer capacitance (represented by $Q_{1}$ ) and the charge transfer resistance (represented by $\left.R_{1}\right)$. The second time constant $\left(Q_{2} R_{2}\right)$ represents the surface layer properties, resulting from the combination of the oxide layer and the coating (the time constants representing the oxide and the coating were too close to be separated with the EIS fitting procedure). The sum of all resistances, apart from $R_{\Omega}$, represents the value of the polarisation resistance $R_{\mathrm{p}}$, which characterizes how the metallic material resists the transfer of electrons to the electroactive species in solution. The higher the $R_{\mathrm{p}}$, the higher the resistance of the metallic material to general (uniform) corrosion.

Figure 6 shows the EIS fitted data obtained by using $R_{\Omega}\left(Q_{2}\left(R_{2}\left(Q_{1} R_{1}\right)\right)\right)$ EEC. The average $C_{1}$ values were similar for the uncoated sample and the coated samples with 6 layers, 
i.e., 3CMC3DEX1 and 3CMC3DEX2.5 (Figure 6a). On the other hand, the coated samples with 5 layers showed different $C_{1}$ properties than the uncoated sample. The 3CMC2DEX1coated sample had higher and the 3CMC2DEX2.5-coated sample lower average $C_{1}$ values compared with the uncoated sample. As expected, the surface layer properties (the average capacitance values $C_{2}$ ) were different for the coated samples compared to the uncoated sample, i.e., for every coated sample, the average $C_{2}$ values were higher than that for the uncoated sample. The latter is a consequence of the coating application. The most important parameter obtained from the EIS fitting procedure is the $R_{\mathrm{p}}$ value. The average $R_{\mathrm{p}}$ values obtained for the coated samples are shown in Figure $6 \mathrm{c}$ (the average $R_{\mathrm{p}}$ values for the uncoated samples are given for comparison [48]). The change in $R_{\mathrm{p}}$ values for the coated samples and uncoated sample is not significant (as tested with the ANOVA with a 95\% confidence level). Therefore, the coatings applied have no significant influence on the general corrosion susceptibility of AISI 316LVM.
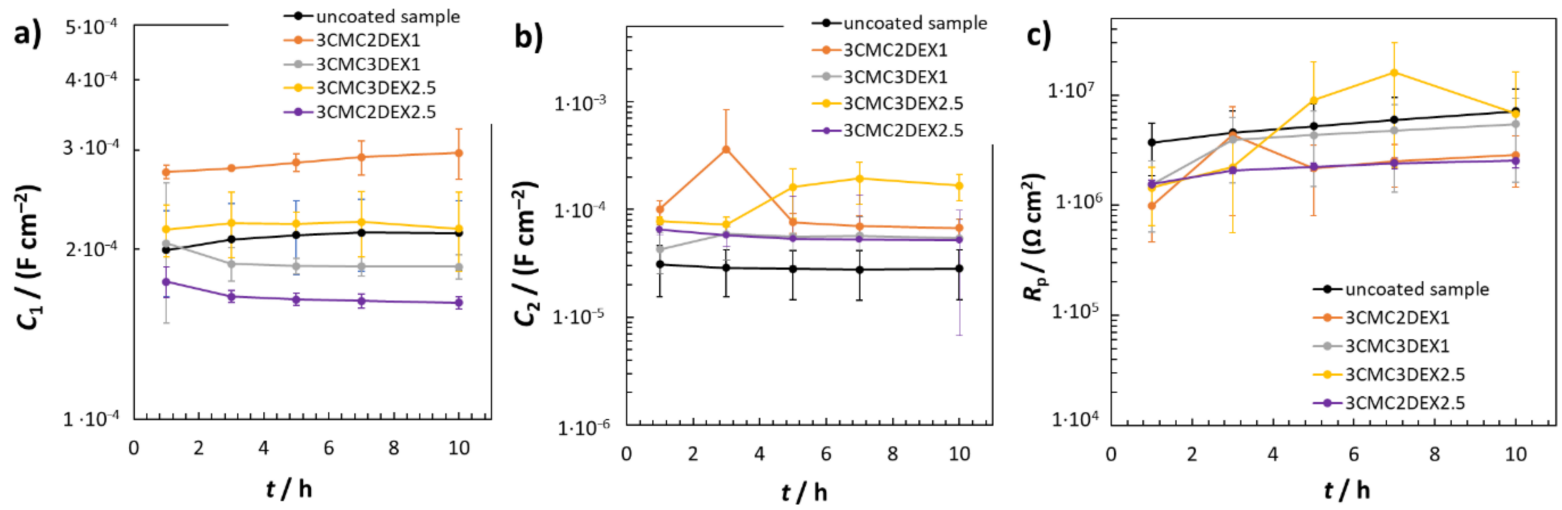

Figure 6. EIS fitted data for uncoated and coated samples; (a) $C_{1}$, (b) $C_{2}$, and (c) $R_{\mathrm{p}}$ fitted values obtained using $R_{\Omega}\left(Q_{2}\left(R_{2}\left(Q_{1} R_{1}\right)\right)\right)$ EEC.

In order to further investigate the possible increased localized corrosion susceptibility of the coated samples compared to the uncoated sample, $\mathrm{CP}$ curve measurements were performed (Figure 7). The breakdown potential $\left(E_{\mathrm{bd}}\right)$, repassivation potential $\left(E_{\mathrm{rp}}\right)$, and $E_{\mathrm{oc}}$ are designated in the figure. The $E_{\mathrm{bd}}$ is determined by extrapolation (as shown in the figure), with the $i$ suddenly increasing due to the surface breakdown, indicating significant localized corrosion (pitting and crevice formation). The $E_{\mathrm{rp}}$ defines the potential, based on which evaluation of the repassivation capability is possible, i.e., if $E_{\mathrm{rp}}$ is at more positive potentials than $E_{\mathrm{OC}}$, the metallic material can repassivate. However, none of the measured samples in Figure 7 has that capability (neither the uncoated nor coated samples). Moreover, the $E_{\mathrm{rp}}$ is similar for all samples. All CP curves are in the cathodic region (in the potential region from $-0.250 \mathrm{~V}$ vs. $E_{\mathrm{oc}}$ to the $\left.E_{\mathrm{oc}}\right)$ at similar $i$. On the other hand, the CP curves in the anodic region (more positive than $E_{\mathrm{oc}}$ ) up to approximately $0.500 \mathrm{~V}$ vs. SCE are at different $i$ for the uncoated and coated samples, i.e., the curves are at lower $i$ for the coated compared to the uncoated samples. The latter indicates that these coatings even mitigate corrosion of AISI 316LVM to a certain degree. Moreover, the $E_{\mathrm{bd}}$ is at similar values for all CP curves, indicating similar localized corrosion behavior for both the uncoated and coated samples. After the breakdown in the reverse scan, the $i$ was higher than that for the forward scan, which is typical of stainless steel materials in chloride solution (once corrosion starts, it can no longer be prevented). Based on the above explanations, the CP curve measurements suggested that the susceptibility to corrosion of the samples with the applied coatings did not increase, but minor corrosion protection of the coated samples can be expected. 


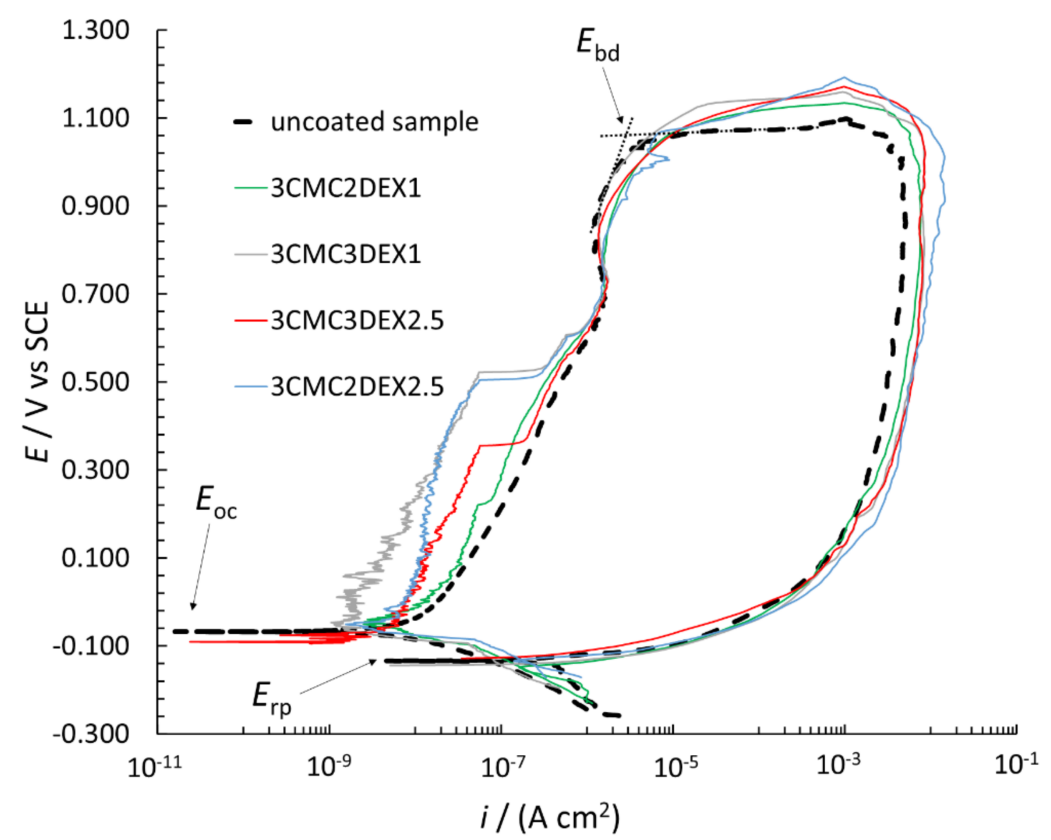

Figure 7. CP curves measured for uncoated and coated AISI 316LVM in 0.9 wt.\% NaCl solution.

\subsection{The In Vitro Effect on Cell Viability, Morphology, and Differentiation}

In order to assess the biocompatibility of the CMC/DEX-coated samples, the cell viability was first analyzed to check if it is affected after exposure to the materials. Such biocompatibility testing is crucial in developing biomedical materials since it is directly connected with their safety and efficacy. For example, it can indicate possible toxic effects during exposure to a specific target tissue, rendering such materials inappropriate for use. A direct contact test was performed for this purpose, whereas all three main cell types in the target tissue (mesenchymal stem cells-MSCs, osteoblasts, and chondrocytes) were used for testing. As the direct contact test demands, the cells were seeded directly onto the coated and uncoated (control) substrates to assess their metabolic activity (MTT assay) after 3 and 6 days as an indirect indicator of cell viability. The results of the cell viability testing are shown in Figure 8. A significant increase in MSC cell viability on all samples compared to control was observed after 6 days (Figure 8a). Similarly, viability increased already after 3 days, except for the samples with a higher DEX concentration (containing $2.5 \mathrm{mg} / \mathrm{mL} \mathrm{DEX)}$, indicating the unfavorable growth effects of high DEX concentrations at the site of immediate contact with the MSCs.

When assessing the viability of the osteoblasts (Figure $8 \mathbf{b}$ ), similar growth potential on coated and uncoated substrates was observed except for 3CMC3DEX2.5, which seems to have inhibited cell viability. The effects were damped throughout by the CMC layer on $3 \mathrm{CMC} 2 \mathrm{DEX} 2.5$, which indicated that the top layer should be either the polymer (CMC) or a layer containing a lower DEX concentration.

Lastly, it was evident that chondrocytes displayed better growth potential on almost all of the coated surfaces, with the lowest values observed for the 3CMC3DEX2.5 sample and the highest values (compared to the control) observed for the 3CMC3DEX1 sample. These results point to a dose-sensitive response to DEX. Considering that all of the cells in this study are of human origin, the obtained results indicate that the prepared samples are safe for use in orthopedic applications. 
a)

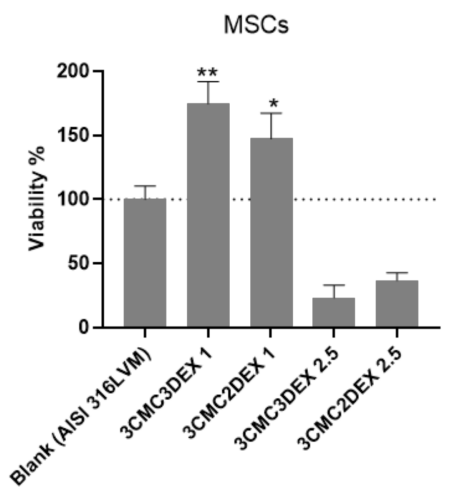

b)

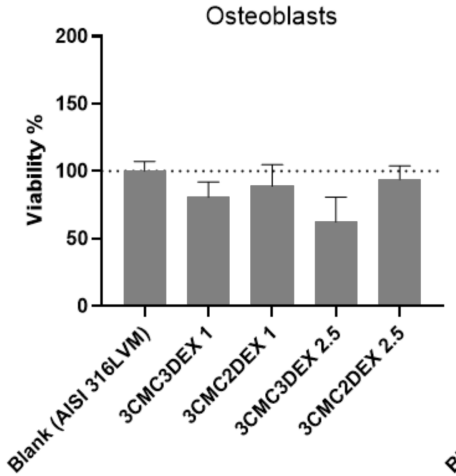

c)

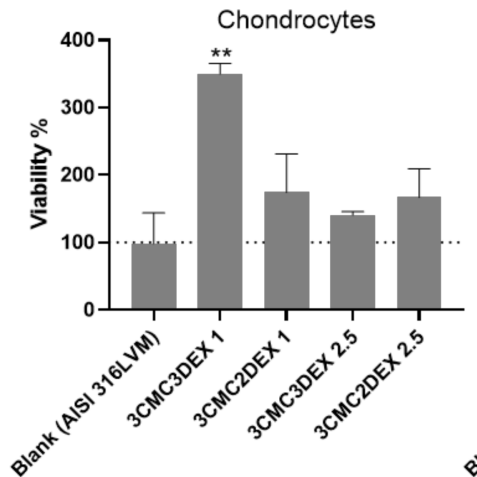

MSCs

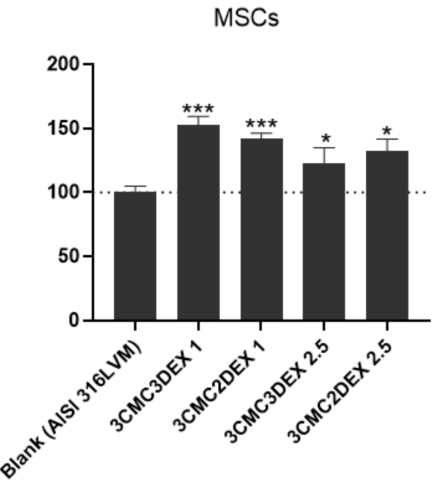

Osteoblasts

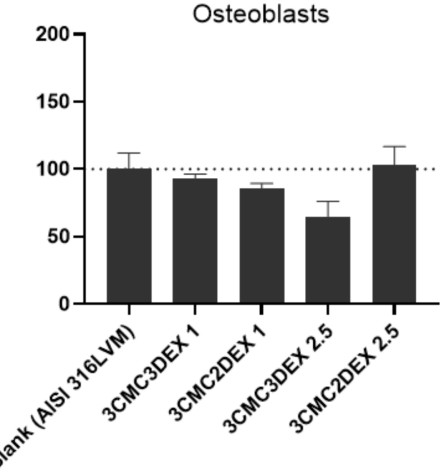

Chondrocytes

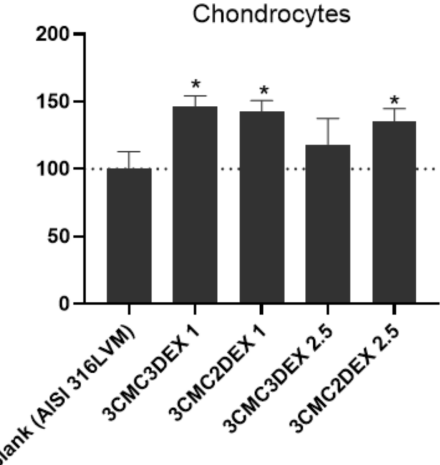

Figure 8. The cell viability testing results of (a) mesenchymal stem cells, (b) osteoblasts, and (c) chondrocytes cultured on uncoated and CMC/DEX-coated AISI 316LVM scaffolds after 3 and 6 days of incubation. Cell viability is expressed as \% relative to control (uncoated AISI 316LVM). Values are shown as the mean \pm standard deviation (three replicates). Statistical significance was defined as ${ }^{*} p<0.05,{ }^{* *} p<0.005$, and ${ }^{* * *} p<0.0005$ compared to the control sample (ANOVA test).

The cells' cytoskeleton (actin) was stained and analyzed with fluorescent microscopy to further analyze the cellular morphology and adhesion. The analysis showed that all of the tested cell types adhered well on all the substrates. However, they displayed various shapes, including different distinct appearances, when grown on CMC or DEX as the direct contact layer. It appears that MSCs grown on the substrate with DEX as the top layer display a more elongated, fibroblast-like morphology. In contrast, cells grown on CMC display a more triangular or star-shaped morphology. Mesenchymal stem cells (MSCs) in general possess a fibroblast-like cell shape, which to some degree enables them to differentiate [52]. Therefore, such a shape is expected for these cells. On the other hand, the star-shaped features observed on coatings with $\mathrm{CMC}$ as the top-most layer were previously reported to be the so-called "rapidly self-renewing cells" [53]. Although the differences in the measured viabilities for the cells grown on different coatings (using the MTT assay) are rather small, these nevertheless seem to be in agreement with this definition. 
The osteoblasts displayed a round, cuboid-like morphology, except for the cells on 3CMC3DEX2.5, where the DEX concentration affected overall cell growth. Apart from the mentioned sample, there were no significantly different morphological features observed between the other three samples regardless whether CMC or DEX was the top layer.

The analysis of the chondrocytes showed flattened or disc-shaped cells when these were grown on CMC or the control substrate compared to the DEX substrate's somewhat elongated cells. Either shape means that the cells grow on the surface (elongated cells are often formed under high cell density conditions and generally indicate a favorable surface for specific cell growth, [54]).

Finally, the potential of developed coatings was investigated to induce MSC differentiation. To this end, immunocytochemical analysis of MSC osteogenic and chondrogenic differentiation markers was performed (Figure 9 and Figure S3 in the Supplementary Materials). Cells were cultured on the substrates for 14 and 21 days, followed by the staining for collagen type I and II, osteocalcin, and aggrecan. Collagen type I and osteocalcin indicate an osteogenic differentiation, whereas collagen type II and aggrecan indicate a chondrogenic differentiation. As shown in Figure 10, increased expression of collagen type I and osteocalcin in the cells grown on substrates containing DEX was observed as the top layer compared to substrates containing CMC as the top layer in the case of uncoated controls. These results indicate that the direct contact of MSCs with DEX favors osteogenic differentiation. No formation of the chondrogenic markers was observed under the experimental conditions (Figure S3 of the Supplementary Materials). Furthermore, immunocytochemical analysis of the osteoblasts and chondrocytes (Figure S4 of the Supplementary Materials) showed that both cell types express their specific matrix proteins when grown on CMC/DEX-coated substrates.
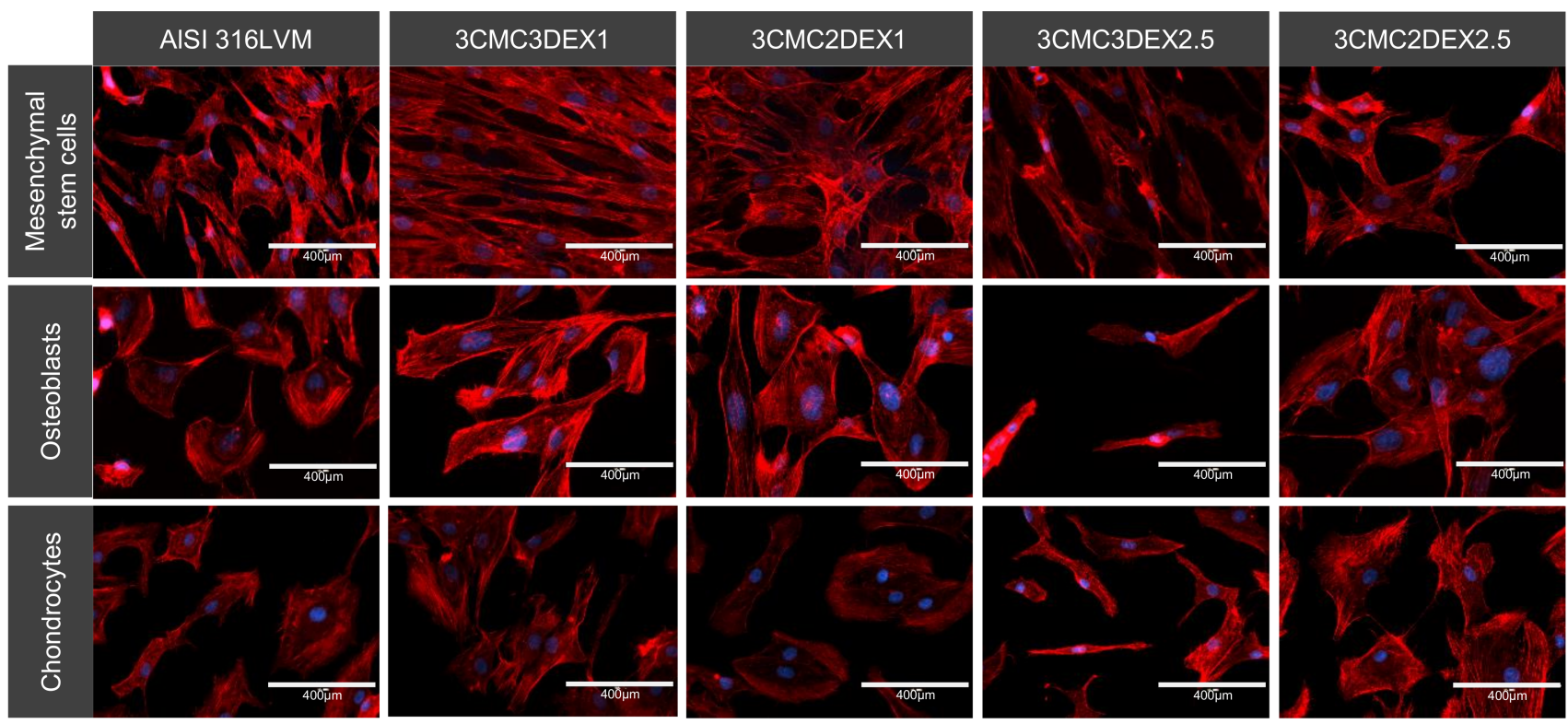

Figure 9. Representative images of the cell morphology and adhesion of different cell types cultured on four different CMC/DEX-coated substrates and controls (AlSI 316LVM) analysed by F-actin staining (red) and visualised with fluorescent microscopy. Cell nuclei were stained with DAPI (blue).

In conclusion regarding the obtained immunocytochemical results, it can be stated that the prepared coatings promote the growth of the main cell types (chondrocytes, osteoblasts, and MSCs) present at the target site of orthopedic interventions (e.g., in hip replacements). The latter was confirmed by viability testing, as well as through specific marker production. Furthermore, the samples with DEX as the top-most layer even promoted osteogenic differentiation, which indicated improved osteointegration of these coatings. The latter is in agreement with the literature, where DEX was shown to be able to promote the 
osteogenic differentiation of MSCs [55]. However, the latter requires controlled drug release, which in this case was achieved by the prepared coatings.
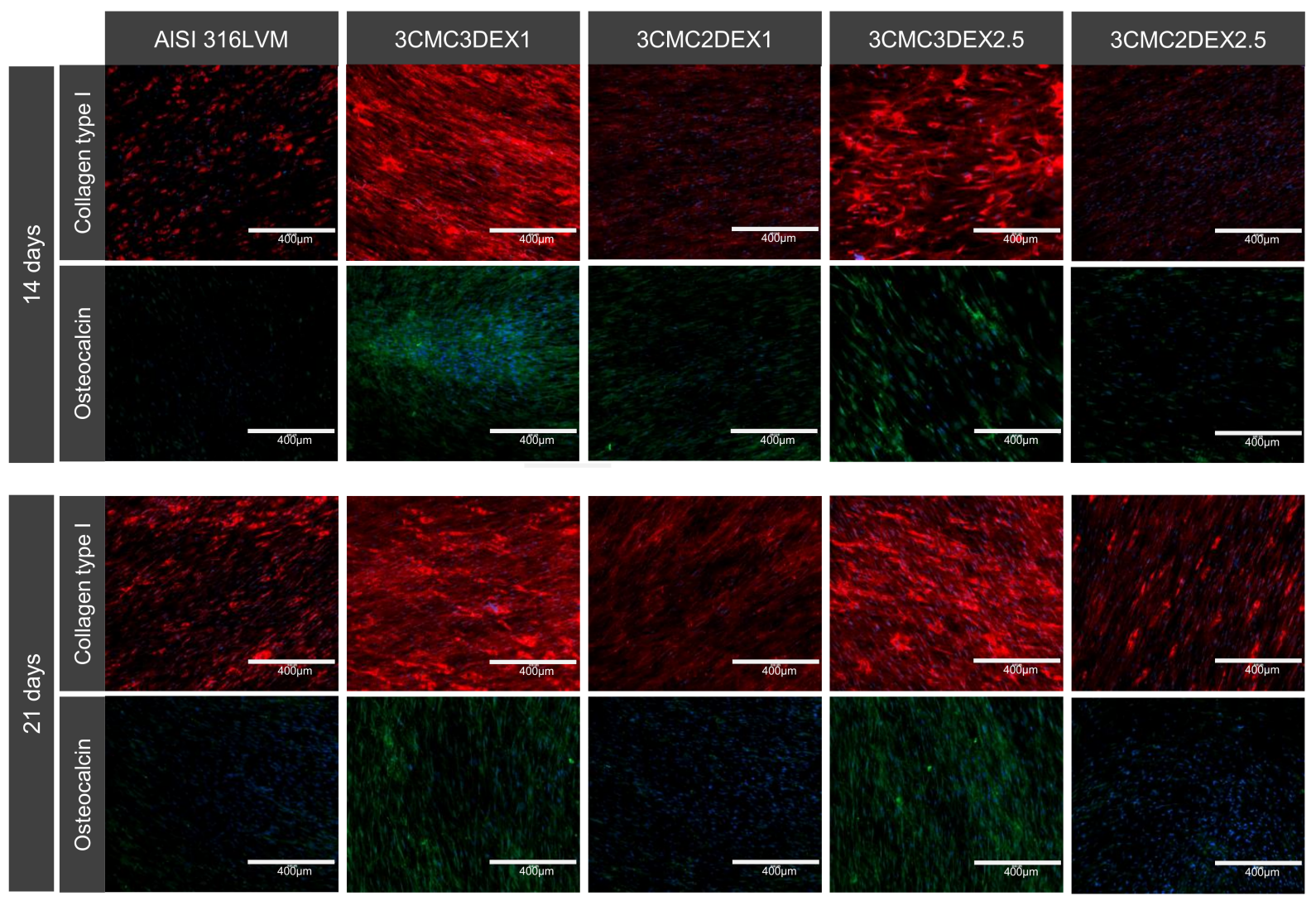

Figure 10. Dexamethasone induces osteogenic differentiation of MSCs. Cells were incubated for 14 and 21 days before immunostaining for osteo-specific markers. Red: collagen type I. Green: osteocalcin. Blue: cell nuclei (DAPI).

\section{Conclusions}

This study presents the development and characterization of multilayer carboxymethylcellulose (CMC)/dexamethasone (DEX) coatings. DEX was used to achieve an antiinflammatory effect and improve the osteointegration potential of the coatings through improved osteogenic differentiation of MSCs. To increase the DEX dosage, $\beta$-cyclodextrin was employed, which significantly increases DEX solubility and thus allows higher DEX content in the coating. The coatings were prepared by spin coating alternating CMC and DEX layers on medical-grade stainless steel (AISI 316LVM). Five-layer (3 CMC and 2 DEX) and six-layer (3 CMC and $3 \mathrm{DEX)}$ ) coatings, with CMC being the first layer in both cases.

Successful layer-by-layer coating formation was confirmed using attenuated total reflectance Fourier transform infrared spectroscopy and atomic force microscopy, which further showed increased surface roughness through coating application. The latter is a favorable feature in terms of cell growth promotion. Furthermore, it was shown that the application of CMC/DEX coatings increases the hydrophilic character of AISI 316LVM. The release of DEX from these coatings followed a zero-order and/or Higuchi model release mechanism. The DEX was released in four stages; the initial "burst" release (in the immersion interval from 0-10 $\mathrm{min})$, followed by fast release (10-30 min), slow release (60-360 $\mathrm{min})$, and the plateau stage (360-4320 $\mathrm{min}$ ).

Electrochemical measurements were carried out to check the possible influence of the applied coatings on the susceptibility of AISI 316LVM to corrosion. Based on the electrochemical impedance spectroscopy measurements and cyclic polarization curve measurements, it was concluded that the coating application does not significantly influence 
the general (uniform) and localized corrosion of AISI 316LVM. A similar general corrosion rate and a similar (or even lower) localized corrosion rate can be expected for the coated samples compared with the uncoated samples in human body solutions.

All prepared coatings improved the viability of the most abundant cell types found at the site of common orthopedic interventions (mesenchymal stell cells-MSC, osteoblasts, and chondrocytes) after six days of culturing. Moreover, coatings with DEX at the topmost layer promoted osteogenic differentiation of MSC, indicating their potential to promote osteointegration.

Supplementary Materials: The following are available online at https://www.mdpi.com/article/ 10.3390/pharmaceutics13040568/s1, Figure S1: ATR-FTIR spectra for comparison of respective components in the multilayer coatings in solution and pure chemicals (powders), Figure S2: Overlay of ATR-FTIR spectra of $\beta$-cyclodextrin ( $\beta$-CD), dexamethasone (DEX), and DEX+CDaq mixture, showing combined spectral features around $1000 \mathrm{~cm}^{-1}$, Figure S3: Immunocytochemical analysis of chondro-specific markers (Collagen type II and aggrecan) in hMSCs after 14 and 21 days of incubation on different CMC/DEX coated and non coated substrates, Figure S4: Immunocytochemical analysis of $\mathrm{hFOB}$ and chondrocytes. The expression of chondrocyte and osteocyte-specific markers was evaluated after 7 days of incubation on different CMC/DEX coated and non-coated substrates.

Author Contributions: Conceptualisation, M.F. and U.M.; data curation, M.F., J.R., M.M., M.Ž., and U.M.; formal analysis, M.F., J.R., M.M., M.Ž., and U.M.; funding acquisition, M.F. and U.M.; investigation, M.F. and U.M.; methodology, M.F. and U.M.; project administration, M.F. and U.M.; resources, M.F. and U.M.; software, M.F., J.R., M.M., M.Ž., and U.M.; supervision, M.F. and U.M.; validation, M.F. and U.M.; visualisation; M.F. and U.M.; roles/writing-original draft, M.F., J.R., M.M., and U.M.; writing-review and editing, M.F. and U.M. All authors have read and agreed to the published version of the manuscript.

Funding: Financial support for this project was provided by the Slovene Ministry of Science, Education, and Sport through grant C3330-19-952029. This research was also funded by the Slovenian Research Agency grant numbers P2-0032, P3-0036, L4-1843, J3-2538, J1-2470, J2-1725, and J1-9169.

Institutional Review Board Statement: Not applicable.

Informed Consent Statement: Not applicable.

Data Availability Statement: The data presented in this study are available on request from the corresponding author.

Conflicts of Interest: The authors declare no conflict of interest.

\section{References}

1. Kelly, B.C.; Vuolo, M. Developing explanatory models for life course shifts in the burden of substance use to Kelly, B.C.; Vuolo, M. Developing explanatory models for life course shifts in the burden of substance use to inform future policy and practice. Int. J. Drug Policy 2021. [CrossRef]

2. van Beek, J.H.; Kirkwood, T.B.; Bassingthwaighte, J.B. Understanding the physiology of the ageing individual: Computational modelling of changes in metabolism and endurance. Interface Focus 2016, 6, 20150079. [CrossRef]

3. Su, N.; Yang, J.; Xie, Y.; Du, X.; Chen, H.; Zhou, H.; Chen, L. Bone function, dysfunction and its role in diseases including critical illness. Int. J. Biol. Sci. 2019, 15, 776-787. [CrossRef] [PubMed]

4. Park, C.Y. Vitamin D in the Prevention and Treatment of Osteoarthritis: 4From Clinical Interventions to Cellular Evidence. Nutrients 2019, 11, 243. [CrossRef] [PubMed]

5. Daud, N.M.; Al-Ashwal, R.H.; Kadir, M.R.A.; Saidin, S. Polydopamine-assisted chlorhexidine Mohd Daud, N.; Hussein AlAshwal, R.; Abdul Kadir, M.R.; Saidin, S. Polydopamine-assisted chlorhexidine immobilisation on medical grade stainless steel 316L: Apatite formation and in vitro osteoblastic evaluation. Ann. Anat. 2018, 220, 29-37. [CrossRef]

6. Maver, U.; Xhanari, K.; Zizek, M.; Korte, D.; Gradisnik, L.; Franko, M.; Finsgar, M. A combination of interdisciplinary analytical tools for evaluation of multi-layered coatings on medical grade stainless steel for biomedical applications. Eur. J. Pharm. Biopharm. 2018, 128, 230-246. [CrossRef]

7. Li, M.; Wu, H.; Wang, Y.; Yin, T.; Gregersen, H.; Zhang, X.; Liao, X.; Wang, G. Immobilization of heparin/poly-l-lysine microspheres on medical grade high nitrogen nickel-free austenitic stainless steel surface to improve the biocompatibility and suppress thrombosis. Mater. Sci. Eng. C Mater. Biol. Appl. 2017, 73, 198-205. [CrossRef] [PubMed]

8. Kang, C.-W.; Fang, F.-Z. State of the art of bioimplants manufacturing: Part I. Adv. Manuf. 2018, 6, 20-40. [CrossRef] 
9. Bukovec, M.; Xhanari, K.; Lešer, T.; Petovar, B.; Finšgar, M. Analysis of the Enameled AISI 316LVM Stainless Steel. J. Mater. Eng. Perform. 2018, 27, 1122-1129. [CrossRef]

10. Eliaz, N. Corrosion of Metallic Biomaterials: A Review. Materials 2019, 12, 407. [CrossRef]

11. Łępicka, M.; Grądzka-Dahlke, M.; Pieniak, D.; Pasierbiewicz, K.; Niewczas, A. Effect of mechanical properties of substrate and coating on wear performance of TiN- or DLC-coated 316LVM stainless steel. Wear 2017, 382, 62-70. [CrossRef]

12. Maver, U.; Xhanari, K.; Zizek, M.; Gradisnik, L.; Repnik, K.; Potocnik, U.; Finsgar, M. Carboxymethyl cellulose/diclofenac bioactive coatings on AISI 316LVM for controlled drug delivery, and improved osteogenic potential. Carbohydr. Polym. 2020, 230, 115612. [CrossRef] [PubMed]

13. Talha, M.; Behera, C.K.; Kumar, S.; Pal, O.; Singh, G.; Sinha, O.P. Long term and electrochemical corrosion investigation of cold worked AISI 316L and 316LVM stainless steels in simulated body fluid. RSC Adv. 2014, 4, 13340-13349. [CrossRef]

14. Kong, J.-Z.; Xu, P.; Cao, Y.-Q.; Li, A.-D.; Wang, Q.-Z.; Zhou, F. Improved corrosion protection of CrN hard coating on steel sealed with TiOxNy-TiN composite layers. Surf. Coat. Technol. 2020, 381, 125108. [CrossRef]

15. Tran, P.A.; O’Brien-Simpson, N.; Palmer, J.A.; Bock, N.; Reynolds, E.C.; Webster, T.J.; Deva, A.; Morrison, W.A.; O'Connor, A.J. Selenium nanoparticles as anti-infective implant coatings for trauma orthopedics against methicillin-resistant Staphylococcus aureus and epidermidis: In vitro and in vivo assessment. Int. J. Nanomed. 2019, 14, 4613-4624. [CrossRef]

16. Yazdani, J.; Ahmadian, E.; Sharifi, S.; Shahi, S.; Maleki Dizaj, S. A short view on nanohydroxyapatite as coating of dental implants. Biomed. Pharmacother. 2018, 105, 553-557. [CrossRef] [PubMed]

17. Surmenev, R.A.; Surmeneva, M.A. A critical review of decades of research on calcium phosphate-based coatings: How far are we from their widespread clinical application? Curr. Opin. Biomed. Eng. 2019, 10, 35-44. [CrossRef]

18. Zykova, Y.; Kudryavtseva, V.; Gai, M.; Kozelskaya, A.; Frueh, J.; Sukhorukov, G.; Tverdokhlebov, S. Free-standing microchamber arrays as a biodegradable drug depot system for implant coatings. Eur. Polym. J. 2019, 114, 72-80. [CrossRef]

19. Kazemzadeh-Narbat, M.; Cheng, H.; Chabok, R.; Alvarez, M.M.; de la Fuente-Nunez, C.; Phillips, K.S.; Khademhosseini, A. Strategies for antimicrobial peptide coatings on medical devices: A review and regulatory science perspective. Crit. Rev. Biotechnol. 2021, 41, 94-120. [CrossRef] [PubMed]

20. Maver, T.; Mohan, T.; Gradisnik, L.; Finsgar, M.; Stana Kleinschek, K.; Maver, U. Polysaccharide Thin Solid Films for Analgesic Drug Delivery and Growth of Human Skin Cells. Front. Chem. 2019, 7, 217. [CrossRef]

21. Mohan, T.; Cas, A.; Bracic, M.; Plohl, O.; Vesel, A.; Rupnik, M.; Zemljic, L.F.; Rebol, J. Highly Protein Repellent and Antiadhesive Polysaccharide Biomaterial Coating for Urinary Catheter Applications. ACS Biomater. Sci. Eng. 2019, 5, 5825-5832. [CrossRef] [PubMed]

22. Gonzalez, J.S.; Mijangos, C.; Hernandez, R. Polysaccharide Coating of Gelatin Gels for Controlled BSA Release. Polymers 2019, 11, 702. [CrossRef] [PubMed]

23. Park, S.; Kim, H.H.; Yang, S.B.; Moon, J.H.; Ahn, H.W.; Hong, J. A Polysaccharide-Based Antibacterial Coating with Improved Durability for Clear Overlay Appliances. ACS Appl. Mater. Interfaces 2018, 10, 17714-17721. [CrossRef]

24. Standert, V.; Borcherding, K.; Bormann, N.; Schmidmaier, G.; Grunwald, I.; Wildemann, B. Antibiotic-loaded amphora-shaped pores on a titanium implant surface enhance osteointegration and prevent infections. Bioact. Mater. 2021, 6, 2331-2345. [CrossRef] [PubMed]

25. Fayed, O.; van Griensven, M.; Tahmasebi Birgani, Z.; Plank, C.; Balmayor, E.R. Transcript-Activated Coatings on Titanium Mediate Cellular Osteogenesis for Enhanced Osteointegration. Mol. Pharm. 2021, 18. [CrossRef]

26. Borcherding, K.; Schmidmaier, G.; Hofmann, G.O.; Wildemann, B. The rationale behind implant coatings to promote osteointegration, bone healing or regeneration. Injury 2020. [CrossRef] [PubMed]

27. Yang, Z.; Xi, Y.; Bai, J.; Jiang, Z.; Wang, S.; Zhang, H.; Dai, W.; Chen, C.; Gou, Z.; Yang, G.; et al. Covalent grafting of hyperbranched poly-L-lysine on Ti-based implants achieves dual functions of antibacteria and promoted osteointegration in vivo. Biomaterials 2021, 269, 120534. [CrossRef]

28. Ibrahim, A.; Dahlqvist, P.; Olsson, T.; Lundgren, D.; Werner, M.; Suhr, O.B.; Karling, P. The clinical course after glucocorticoid treatment in patients with inflammatory bowel disease is linked to suppression of the hypothalamic-pituitary-adrenal axis: A retrospective observational study. Ther. Adv. Gastroenterol. 2017, 10, 829-836. [CrossRef]

29. Andreasen, C.M.; Ding, M.; Andersen, T.L.; Overgaard, S. Effects of substitute coated with hyaluronic acid or poly-lactic acid on implant fixation: Experimental study in ovariectomised and glucocorticoid-treated sheep. J. Tissue Eng. Regen. Med. 2018, 12, e1122-e1130. [CrossRef] [PubMed]

30. Lewallen, E.A.; Riester, S.M.; Bonin, C.A.; Kremers, H.M.; Dudakovic, A.; Kakar, S.; Cohen, R.C.; Westendorf, J.J.; Lewallen, D.G.; van Wijnen, A.J. Biological strategies for improved osseointegration and osteoinduction of porous metal orthopedic implants. Tissue Eng. Part. B Rev. 2015, 21, 218-230. [CrossRef]

31. Zhang, Y.; Fang, C.; Zhang, S.; Campbell, R.E.; Serpe, M.J. Controlled Osteogenic Differentiation of Human Mesenchymal Stem Cells Using Dexamethasone-Loaded Light-Responsive Microgels. ACS Appl. Mater. Interfaces 2021, 13, 7051-7059. [CrossRef]

32. Sordi, M.B.; Curtarelli, R.B.; da Silva, I.T.; Fongaro, G.; Benfatti, C.A.M.; de Souza Magini, R.; Cabral da Cruz, A.C. Effect of dexamethasone as osteogenic supplementation in in vitro osteogenic differentiation of stem cells from human exfoliated deciduous teeth. J. Mater. Sci. Mater. Med. 2021, 32. [CrossRef] [PubMed] 
33. Najafi, F.; Salami-Kalajahi, M.; Roghani-Mamaqani, H.; Kahaie-Khosrowshahi, A. A comparative study on solubility improvement of tetracycline and dexamethasone by poly(propylene imine) and polyamidoamine dendrimers: An insight into cytotoxicity and cell proliferation. J. Biomed. Mater. Res. A 2020, 108, 485-495. [CrossRef]

34. Fiorica, C.; Palumbo, F.S.; Pitarresi, G.; Bongiovì, F.; Giammona, G. Hyaluronic acid and beta cyclodextrins films for the release of corneal epithelial cells and dexamethasone. Carbohydr. Polym. 2017, 166, 281-290. [CrossRef] [PubMed]

35. Jiang, K.; Weaver, J.D.; Li, Y.; Chen, X.; Liang, J.; Stabler, C.L. Local release of dexamethasone from macroporous scaffolds accelerates islet transplant engraftment by promotion of anti-inflammatory M2 macrophages. Biomaterials 2017, 114, 71-81. [CrossRef] [PubMed]

36. Daghrery, A.; Aytac, Z.; Dubey, N.; Mei, L.; Schwendeman, A.; Bottino, M.C. Electrospinning of dexamethasone/cyclodextrin inclusion complex polymer fibers for dental pulp therapy. Colloids Surf. B: Biointerfaces 2020, 191, 111011. [CrossRef] [PubMed]

37. Tanaka, S.; Takashima, Y.; Murayama, H.; Tsuchiya, S. Solubility and distribution of dexamethasone acetate in oil-in-water creams and its release from the creams. Chem. Pharm. Bull. 1985, 33, 3929-3934. [CrossRef] [PubMed]

38. Sid, D.; Baitiche, M.; Elbahri, Z.; Djerboua, F.; Boutahala, M.; Bouaziz, Z.; Le Borgne, M. Solubility enhancement of mefenamic acid by inclusion complex with beta-cyclodextrin: In silico modelling, formulation, characterisation, and in vitro studies. J. Enzym. Inhib. Med. Chem. 2021, 36, 605-617. [CrossRef]

39. Singh, P.; Wu, L.; Ren, X.; Zhang, W.; Tang, Y.; Chen, Y.; Carrier, A.; Zhang, X.; Zhang, J. Hyaluronic-acid-based beta-cyclodextrin grafted copolymers as biocompatible supramolecular hosts to enhance the water solubility of tocopherol. Int. J. Pharm. 2020, 586, 119542. [CrossRef] [PubMed]

40. Loftsson, T.; Jarho, P.; Másson, M.; Järvinen, T. Cyclodextrins in drug delivery. Expert Opin. Drug Deliv. 2005, 2, 335-351. [CrossRef] [PubMed]

41. Erbil, H.Y. Dependency of Contact Angles on Three-Phase Contact Line: A Review. Colloids Interfaces 2021, 5, 8. [CrossRef]

42. Naranda, J.; Gradišnik, L.; Gorenjak, M.; Vogrin, M.; Maver, U. Isolation and characterisation of human articular chondrocytes from surgical waste after total knee arthroplasty (TKA). PeerJ 2017, 5, e3079. [CrossRef]

43. Song, R.; Murphy, M.; Li, C.; Ting, K.; Soo, C.; Zheng, Z. Current development of biodegradable polymeric materials for biomedical applications. Drug Des. Dev. Ther. 2018, 12, 3117-3145. [CrossRef] [PubMed]

44. Patra, J.K.; Das, G.; Fraceto, L.F.; Campos, E.V.R.; Rodriguez-Torres, M.D.P.; Acosta-Torres, L.S.; Diaz-Torres, L.A.; Grillo, R.; Swamy, M.K.; Sharma, S.; et al. Nano based drug delivery systems: Recent developments and future prospects. J. Nanobiotechnol. 2018, 16, 71. [CrossRef]

45. Gittens, R.A.; McLachlan, T.; Olivares-Navarrete, R.; Cai, Y.; Berner, S.; Tannenbaum, R.; Schwartz, Z.; Sandhage, K.H.; Boyan, B.D. The effects of combined micron-/submicron-scale surface roughness and nanoscale features on cell proliferation and differentiation. Biomaterials 2011, 32, 3395-3403. [CrossRef] [PubMed]

46. Osathanon, T.; Bespinyowong, K.; Arksornnukit, M.; Takahashi, H.; Pavasant, P. Human osteoblast-like cell spreading and proliferation on Ti-6Al-7Nb surfaces of varying roughness. J. Oral Sci. 2011, 53, 23-30. [CrossRef] [PubMed]

47. Massart, D.L.; Vandeginste, B.G.M.; Buydens, L.M.; Jong, S.D.; Lewi, P.J.; Smeyers-Verbeke, J. Handbook of Chemometrics and Qualimetrics: Part A; Elsevier: Amsterdam, The Netherlands, 1997.

48. Finšgar, M.; Uzunalic, A.P.; Stergar, J.; Gradisnik, L.; Maver, U. Novel chitosan/diclofenac coatings on medical grade stainless steel for hip replacement applications. Sci. Rep. 2016, 6, 1-17. [CrossRef] [PubMed]

49. Raistrick, I.D.; Franceschetti, D.R.; Macdonald, J.R. Impedance Spectroscopy Theory, Experiment, and Application, 2nd ed.; John Wiley \& Sons Inc.: Hoboken, NJ, USA, 2005.

50. Finšgar, M.; Kek Merl, D. 2-Mercaptobenzoxazole as a copper corrosion inhibitor in chloride solution: Electrochemistry, 3Dprofilometry, and XPS surface analysis. Corros. Sci. 2014, 80, 82-95. [CrossRef]

51. Finšgar, M.; Kek Merl, D. An electrochemical, long-term immersion, and XPS study of 2-mercaptobenzothiazole as a copper corrosion inhibitor in chloride solution. Corros. Sci. 2014, 83, 164-175. [CrossRef]

52. Schneider, N.; Goncalves Fda, C.; Pinto, F.O.; Lopez, P.L.; Araujo, A.B.; Pfaffenseller, B.; Passos, E.P.; Cirne-Lima, E.O.; Meurer, L.; Lamers, M.L.; et al. Dexamethasone and azathioprine promote cytoskeletal changes and affect mesenchymal stem cell migratory behavior. PLoS ONE 2015, 10, e0120538. [CrossRef]

53. Haasters, F.; Prall, W.C.; Anz, D.; Bourquin, C.; Pautke, C.; Endres, S.; Mutschler, W.; Docheva, D.; Schieker, M. Morphological and immunocytochemical characteristics indicate the yield of early progenitors and represent a quality control for human mesenchymal stem cell culturing. J. Anat. 2009, 214, 759-767. [CrossRef] [PubMed]

54. Ormerod, E.J.; Rudland, P.S. Isolation and differentiation of cloned epithelial cell lines from normal rat mammary glands. In Vitro Cell. Dev. Biol. 1985, 21, 143-153. [CrossRef] [PubMed]

55. Langenbach, F.; Handschel, J. Effects of dexamethasone, ascorbic acid and beta-glycerophosphate on the osteogenic differentiation of stem cells in vitro. Stem Cell Res. Ther. 2013, 4, 117. [CrossRef] [PubMed] 